



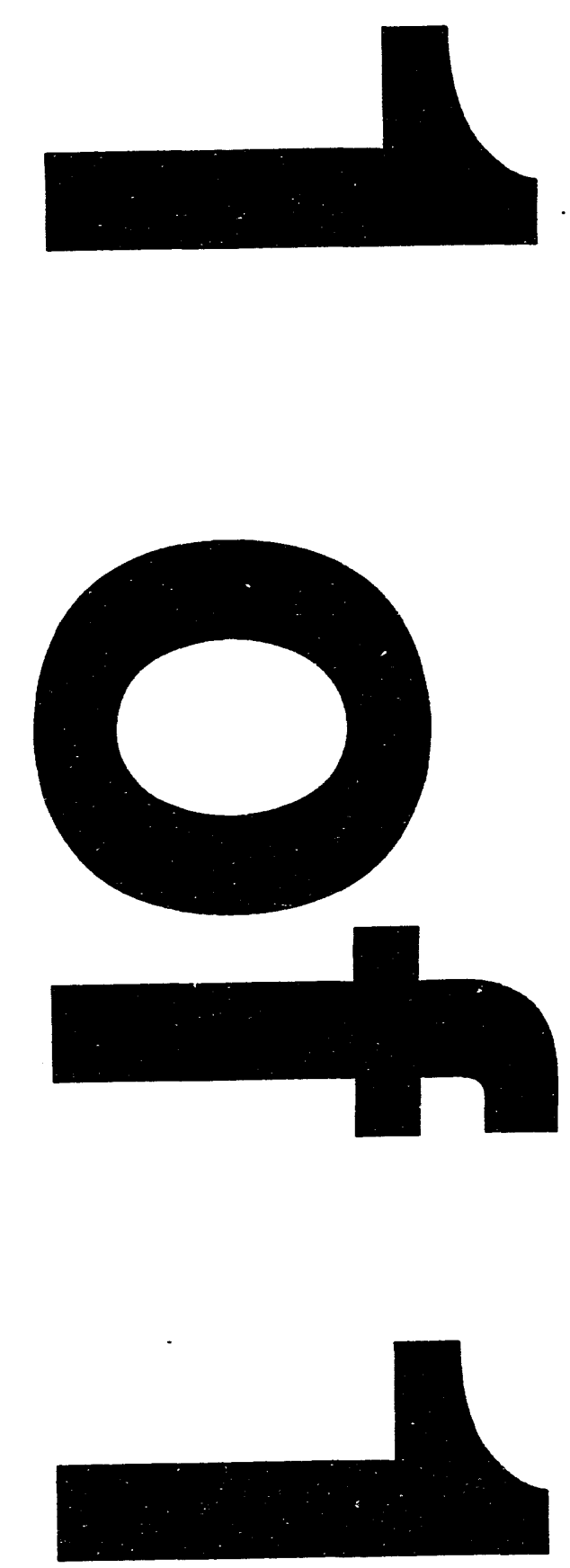
Distribution

Category UC-261

SAND93-7015

Unlimited Release

Printed March 1994

\title{
A USER'S MANUAL FOR THE PROGRAM \\ TRES4: \\ RANDOM VIBRATION ANALYSIS OF \\ VERTICAL-AXIS WIND TURBINES IN TURBULENT WINDS*
}

\author{
prepared by \\ David Malcolm Associates Inc \\ Mississauga, Ontario, Canada
}

December 1991

\begin{abstract}
TRES4 is a software package that works with the MSC/NASTRAN finite element analysis code to conduct random vibration analysis of vertical-axis wind turbines. The loads on the turbine are calculated in the time domain to retain the nonlinearities of stalled aerodynamic loadings. The loads are transformed into modal coordinates to reduce the number of degrees of freedom. Power spectra and cross spectra of the loads are calculated in the modal coordinate system. These loads are written in NASTRAN Bulk Data format to be read and applied in a random vibration analysis by NASTRAN. The resulting response is then transformed back to physical coordinates to facilitate user interpretation.
\end{abstract}

*The work described in this report was performed for Sandia National Laboratories under Contract No. DE-AC04-76DP00789.

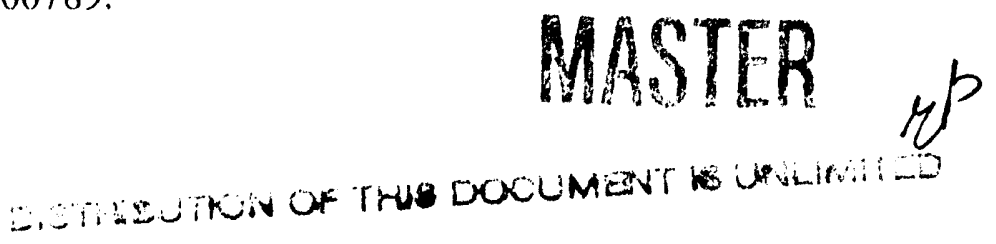


1. INTRODUCTION 4

1.1 Background 4

1.2 Objectives 4

2. MATHEMATICAL MODEL

2.1 Basic Algorithm 5

2.2 Aerodynamic Model 5

3. ORGANIZATION OF SOLUTION

3.1 NASTRAN Input File 7

3.2 Extraction of Real Eigenvectors $\quad 8$

3.3 Preparation of Aerodynamic Loads (TRES4) 8

3.4 NASTRAN Frequency Response Analysis 8

3.5 Post-Processing of Results 9

4. BASIC INPUT DATA 10

4.1 Units 10

4.2 Format 10

4.3 Explanation of Input Variables 10

4.4 Control of Output 12

4.5 ZSET Option 12

4.6 Suppression of Modes 13

4.7 Turbulence Models 13

5. COMPILATION \& RUNNING

5.1 Machine Dependency 14

$\begin{array}{ll}5.2 \text { Limitations } & 14\end{array}$

$\begin{array}{lll}5.3 & \text { Linking } & 15\end{array}$

6. AIRFOIL DATA 15

7. OUTPUT VIA TRESD.FOR 16 
$\begin{array}{lll}\text { 8.1 Program AEROB5.FOR } & 17\end{array}$

$\begin{array}{lll}8.2 & \text { Basic Input File } & 17\end{array}$

$\begin{array}{ll}\text { 9. REFERENCES } & 18\end{array}$

\section{LIST OF FIGURES}

1. SNL/USDA 34m Test Bed Finite Element Model $\quad 19$

2. Schematic of Total Solution Procedure 20

APPENDICES
A. NASTRAN Bulk Data Input File
B. Sample Solution 3 Input
C. Sample Solution 64 \& 71 Input
D. Sample TRESI.OUT File
E. Sample Airfoil Data File
F. Sample Basic Input File (for $34 \mathrm{~m}$ Test Bed)
G. Sample Basic Input File for AEROB5.FOR 


\section{INTRODUCTION}

\subsection{Background}

Vertical axis wind turbines (VAWTs) are machines designed to extract energy from the wind. They differ from horizontal axis wind turbines (HAWTs) in that the structure revolves about an axis that is vertical. One consequence of this arrangement is that under a steady wind the forces experienced by the structure are periodic with frequencies that are multiples of the rotor speed. These cyclic forces give rise to fatigue stresses.

Under non-steady, or turbulent winds, cyclic forces are experienced at frequencies other than the harmonic frequencies. In some circumstances the effect of turbulence on the overall fatigue loading is small, but in other circumstances it has been observed to be considerable. It is, therefore, of importance to be able to predict the structural response under turbulent conditions.

To achieve this goal it is necessary to add considerable complexity to the solution procedure. Not only has the passage of turbulent air to be modeled, but the structural response to (partially) random excitation must be obtained. The first step has been tackled using the method set out by Veers (1984); the second step has been achieved by the use of appropriate MSC/NASTRAN solutions with certain modifications. This manual is concerned with the FORTRAN program TRES4, which prepares the aerodynamic loading for the NASTRAN analysis.

\subsection{Objectives}

The purpose of this document is, first, to give the reader (who is assumed to have some acquaintance with wind turbine design) some understanding of the basic mathematics. Second, it is intended to give detailed instructions for the use of the program TRES4 and to advise on possible problems. 


\section{MATHEMATICAL MODEL}

\subsection{Basic Algorithm}

Dynamic structural analysis may be carried out in either the time domain or in the frequency domain. The former involves a step-by-step integration procedure which, for the required number of rotor revolutions (preferably greater than 200), can be very demanding on computer resources and can lead to excessive input and output data. Analysis in the frequency domain is less demanding on data and computation, but both input and output require some interpretation. The second approach has been selected for this procedure.

In order to use the program TRES4 intelligently, some understanding of the basic method is of value. A full review can be found in Malcolm (1988).

If stochastic loads at degrees of freedom $a$ and $b$ are related by cross spectral densities (csd's) $S_{a b}(f)$, then the power spectral density (psd) of the response at degree of freedom $i$ is $S_{i}(f)$ and is given by

$$
S_{i}(f)=H_{i a}(f) H_{i b}^{*}(f) S_{a b}(f)
$$

where $H_{i a}(f)$ is the frequency response function between degrees of freedom $i$ and $a$ and * indicates the complex conjugate.

In a typical Darrieus rotor finite element model there are about 200 degrees of freedom having aerodynamic loads over a frequency width, which may be discretized into about 100 divisions. The number of terms in the full input would, therefore, be of the order of $2 \times 10^{6}$. One method of reducing this large file, and the corresponding calculations, is to express the behavior in terms of the modes of natural vibration, thereby reducing the degrees of freedom from 200 to about 20 .

The input psd's and csd's can still be very long. Some options exist in TRES4 to help reduce this length by neglecting small values.

MSC/NASTRAN does not normally accept loads as modal components; and it is, therefore, necessary to include modifications (DMAP Alters) to accomplish this.

\section{2 Aerodynamic Model}

The aerodynamic model used is the double multiple streamtube (DMST) model (Paraschivoiu, 1984) that has been found to give good predictions of performance without undue computation time. The model carries out an iterative momentum balance 
calculation at each streamtube into which the swept area is divided at each azimuth position.

In steady winds this calculation need be done for one revolution only. In a turbulent wind it must be done for a number of revolutions so that the full variability of the wind can be represented. 


\section{ORGANIZATION OF SOLUTION}

The total solution procedure consists of five steps.

1. Preparation of MSC/NASTRAN finite element model of rotor and supports.

2. Extraction of real eigenvectors and eigenvalues of the stationary rotor.

3. Use of TRES4 to prepare stochastic aerodynamic loading.

4. Modal frequency response using a suitable NASTRAN solution.

5. Post-processing of output.

\subsection{NASTRAN Input File}

An example of an MSC/NASTRAN bulk data file is included as Appendix A. It may be prepared in one of a number of ways, although each requires careful evaluation of the structural and inertial properties of the main members.

There is sometimes a choice of ways to model a certain member or feature. TRES4, which reads the NASTRAN bulk file, requires that certain restrictions apply. These are:

All elements that are to have aerodynamic loads must consist of CBEAM members.

- There is no need to offset the center of mass or center of twist from the grid points.

The beam members must not be tapered.

The grid points of the first blade must begin with number 100 (at the top or at the bottom of the rotor) and be numbered consecutively.

The grid points of the second blade must likewise begin with the number 200 .

Column grid points must have numbers lying between 1 and 99 .

All other grid point numbers (not on the column or blades) must lie above 299 .

To incorporate aerodynamic loading on the central column, the column diameter must be placed in field 10 of the appropriate GRID cards. This field will be read by TRES 4 but ignored by NASTRAN. 


\subsection{Extraction of Real Eigenvectors}

The eigenvectors of the stationary rotor are used as generalized coordinates for the aerodynamic loads calculated by TRES4. It is, therefore, necessary to extract these by a suitable NASTRAN solution and to output this information using the PUNCH output option.

MSC/NASTRAN version 66 solutions 3 or 63 or 103 may be used. Appendix B contains sample executive and case control sections for a solution 3 run. The operating system of the computer must be used to ensure that the output is saved under a suitable name.

Appendix A also includes a sample REIG card controlling the extraction of eigenvalues and vectors. It is important that this card and the ASETI cards (for reduction of the dynamic problem) must be the same in this NASTRAN solution as in the subsequent frequency response analyses (see Section 3.4).

\subsection{Preparation of Aerodynamic Loads (TRES4)}

As Figure 2 indicates, TRES4, which generates the stochastic aerodynamic loads, requires a number of input sources. These are:

- $\quad$ NASTRAN bulk data file (see Section 3.1)

- $\quad$ TRES4 input variables (see Section 4)

- Airfoil data (see Section 6)

- Eigenvectors of the stationary rotor (see Section 3.2)

Figure 2 also shows that TRES4 produces two output files as well as two temporary storage files. One of these (TRES.OUT) contains an echo of the input variables as well as output concerning the variance of the modal loads and output power spectral densities in a format suitable for reading by a post-processing program. The second file (TRESI.OUT) contains data in a format for NASTRAN.

\subsection{NASTRAN Frequency Response Analysis}

Modal frequency response can be carried out using either solutions 30 (a rigid format solution sequence) or 71 (a superelement solution sequence) or 111 (a "structured" solution sequence). This analysis is complicated by the requirements of including the rotating frame effects, which require an initial solution 64 (geometric nonlinear analysis using at least four subcases) in order to incorporate the stiffening effects of the centrifugal forces. One approach is to pass the data base from solution 64 to the subsequent analysis; since the data bases from structured and unstructured solutions are 
not compatible, and some changes need to be made to input a data base into a rigid format, the most acceptable choice is the use of solution 71 .

Sample executive and case control sections for the combined solution 64 and 71 run are included as Appendix C. Of importance in the solution 64 bulk data is the RFORCE card, which defines the centrifugal loading. The GRAV (gravity) and FORCE (guy cable thrust) should, strictly, also be included, but are probably less significant.

Solution 71 requires the inclusion of a number of modifications. The first is the inclusion of Coriolis and whirling effects. This is done through matrix manipulation (Alter 1087), which relies on basic symmetric and skew symmetric matrices that are defined by DMI cards included at the end of the bulk data file. In addition, the PARAM, OMEGA card must be included to indicate the rotor speed (in radians/s).

Aeroelastic effects on the effective stiffness and damping matrices may also be incorporated as K2PP and B2PP matrices through DMIG cards. If these effects are not included, then it is important to include an estimate of the critical damping of the various modes through a TABDMPl card, as the example in Appendix D illustrates. This requires a knowledge of the mode shapes of the real eigenvectors and an understanding of what damping to expect in each mode. It has been noted that the blade flatwise symmetric and asymmetric modes experience the most aeroelastic damping.

The consequence of including too little or no damping will be very high response at the natural frequencies of the operating rotor, which will result in overdesign of the rotor components.

\subsection{Post-Processing of Results}

The output from the NASTRAN random analysis module is in the form of discrete power spectral densities for each selected response. The manner in which these output are requested is illustrated in Appendix $C$.

Rapid and easy evaluation of results is always important. The designer is interested in knowing the total variance of a particular response and what frequencies dominate this response. The spectra must be extracted from the NASTRAN output by a program designed to read the file or by manual editing. The data may then be plotted by any of a number of commercially available programs. Likewise, the spectra of modal loads included in the file TRES.OUT may be extracted and plotted.

The exact manner in which this post-processing is done will depend on the user's preferences and available hardware and software. It is not, therefore, included with the program TRES4. 


\section{BASIC INPUT DATA}

\subsection{Units}

TRES4E uses English (imperial) units in contrast to TRES4EM, which uses SI units. The units for the input file variables are given adjacent to the variables as they are described below.

\subsection{Format}

All comment lines must begin with a ' $\$$ ' in column one (as in NASTRAN). Free format is used except where noted. An example of a basic input file for the $34 \mathrm{~m}$ Test Bed is included as Appendix F.

\subsection{Explanation of Input Variables}

Line 1 (free format)

HT inches height of rotor between blade intersection points

DIA inches maximum diameter of rotor

HMR inches mid-rotor height above ground

RPM rpm rotor speed

VBAR mph mean ambient wind speed at mid-rotor

WSE exponent defining vertical wind shear

DELT seconds time interval in the definition of wind velocity series

ARHO $\mathrm{lb} / \mathrm{ft}^{3}$ air density

Line 2 (free format)

C1X

$\mathrm{C} 2 \mathrm{X}$

$\mathrm{C} 1 \mathrm{Y}$

$\mathrm{C} 2 \mathrm{Y}$

Z0 $\mathrm{m} \quad$ roughness height used in certain expressions for turbulence

DECAY

VAR

NSOFT

FMIN

CMIN spectrum for $\mathrm{X}$ (longitudinal) and $\mathrm{Y}$ (lateral) directions coefficients $\mathrm{C} 1$ and $\mathrm{C} 2$ for use in Frost \& Turner's turbulence

decay coefficient used to define coherence of cds's of wind velocities. See Veers 1984.

turbulence intensity of longitudinal wind (standard deviation/mean value). Used in the Kaimal (stable) and the von Karman (neutral) turbulence expressions.

the number of time intervals over which the velocity time series are smoothed. It is recommended that NSOFT $=1$.

an entire csd will be omitted if its variance is below a value equal to FMIN* (minimum of all NEIG psd's)

a minimum value of a certain frequency component of a modal load csd below which it will be omitted from the output 
Line 3 (free format)

ISPEC'T

type of formula to be used for atmospheric turbulence (see Section 4.7)

Line 4 (free format)

NHT

number of vertical divisions into which the swept area is divided for definition of wind speed time series

NDIA number of lateral divisions into which the swept area is divided for definition of wind speed time series. See Section 5.2 for limitations.

NEIG

NT

NREV number of real eigenvectors used as generalized coordinates in modal solution. See Section 5.2 for limitations.

number of intervals per rotor revolution in DMST routine (must be a power of 2). See Section 5.2 for limitations.

number of rotor revolutions in each analysis. NREV must be a power of 2 .

NSECT number of different sections on each blade corresponding to the number of PBEAM cards required to define the CBEAM blade elements.

NLOOP number of repeated analyses used to generate an ensemble of load spectra (and correct csd values)

NPMAX the maximum frequency (in multiples of rotor speed) for analysis and for output

NDIV number of divisions between per-rev frequencies used in output (NREV must be evenly divisible by NDIV)

NOUT

NSUP

number of loops after which modal loads will be output to TRES.OUT. number of eigenvectors to be suppressed in NASTRAN analysis. See Sections 4.4 and 4.6 .

Lines 5, 6, and 7 (A3 format)

These contain YES/NO requests for upwind and downwind dynamic stall and for use of the ZSET option (see Section 4.4)

Line 8 (free format)

IPRINT

option number for output of csd's. Only option \#1 is now valid.

Next NSECT lines (format I4,A8,F10.2)

I section number corresponding to PBEAM id number $(100+\mathrm{I})$

TYPE(I) 8-character alphanumeric description of airfoil profile (which must

$\mathrm{CH}(\mathrm{I})$ inches blade chord

Next 1 up to NEIG lines (free format)

I

DAMP(I) eigenvalue number

critical damping for mode $I$. Note that only non-zero values need be given, but that at least one line must be entered. 
Next NSUP lines (free format)

I

mode number to be suppressed from the analysis (see Sections

4.4 and 4.6)

\subsection{Control of Output}

The objective of the analysis is to obtain meaningful results without dealing with excessive input and output. The definition of what is excessive will depend on the particular computing environment. For example, creating the TRESI.OUT file on a PC and sending the NASTRAN input file to another computer via a modem is more restrictive than working directly with a mainframe computer. The maximum size of TRES4 output is also controlled by the present dimension limitations in the program, which is discussed in Section 5.2.

One method of limiting TRES4 output size is to limit the number of eigenvectors (NEIG) used. It has been found that up to about 22 modes is required to allow the modal formulation of a Darrieus rotor to be an acceptable approximation.

Additionally some modes may be suppressed (NSUP > O). An indication of what modes are associated with less load can be found by inspection of the TRES.OUT file. It must be pointed out, however, that due to Coriolis coupling of modes, the lack of a certain modal load does not necessarily imply lack of response in that mode.

The resolution of the power and cross spectral densities submitted to NASTRAN can be controlled. The maximum number of intervals between each per-rev frequency is NREV (which must also be a power of 2). If a larger interval is wanted, then NDIV should be put equal to an integer less than NREV and which is evenly divisible into NREV. For average size rotors, a value of NDIV=16 may be adequate; but for slower rotor speeds, up to NDIV=32 may be desirable.

Many of the csd elements are close to zero owing to the lack of correlation between some modal loads, especially at frequencies that are not rotor speed harmonics. These can be removed from the tabular listing by defining a floor value (CMIN) below which they are omitted. Likewise FMIN controls the floor of the total csd variance below which the entire csd table (or part of it) will be omitted. The FMIN value is the multiple applied to the lowest of the modal load psd variances.

\subsection{ZSET Option}

The number and location of finite element nodes on the blades is usually governed by structural considerations. For example, nodes may be more closely spaced near the root connections. However, the DMST aerodynamic model may not require the same detail, and much computer time may be wasted in this way. 
The ZSET is a subset of the blade finite element nodes that is used in the aerodynamic modeling. It is included in the bulk data file, but is preceded by a ' $\$$ ' so it is ignored by NASTRAN. Following '\$ZSET', up to 20 nodes may be listed in format $(A 5,20 I 4)$ as illustrated in Appendix A.

It is recommended that the ZSET not contain fewer than about 16 nodes and that nodes at the intersection of different airfoils and/or chords be included.

\subsection{Suppression of Modes}

It is sometimes found that a certain high frequency mode is important in the response while some lower frequency modes are relatively unimportant. Exclusion of the latter can shorten the input file and decrease computing time.

Modes can be suppressed by including their total number as NSUP and listing them as described in Section 4.3 and as illustrated in Appendix F.

\subsection{Turbulence Models}

The variable ISPECT is a number corresponding to the type of formula used for the atmospheric turbulence. This is a subject on which much has been and, no doubt, will be written (see Malcolm 1990).

There are five possible turbulence expressions available within the routine TSPECT of TRES4. They are:

1. Kaimal/Strickland formula (stable atmospheres)

This is dependent on the overall variance and the $\mathrm{C} 1$ and $\mathrm{C} 2$ values.

2. Frost \& Turner

This requires $\mathrm{Cl}, \mathrm{C} 2$ and $\mathrm{Z} 0$ values.

3. Kaimal formula (neutral atmospheres)

This requires $\mathrm{C} 1, \mathrm{C} 2$ and $\mathrm{Z} 0$ values.

4. von Karman/Fordham (neutral atmospheres)

This requires overall variance, $\mathrm{Cl}$ and $\mathrm{C} 2$ values, and also a measure of turbulence length--at present set at $120 \mathrm{~m}$.

5. von Karman/Fordham (neutral atmospheres and dependent on height and roughness)

As well as a $\mathrm{Z} 0$ value, this expression requires $\mathrm{Cl}, \mathrm{C} 2$ and a characteristic length, also preset at $120 \mathrm{~m}$. 


\section{COMPILATION AND RUNNING}

\subsection{Machine Dependency}

The program TRES4E, as listed in Appendix G, has been tailored to run on an IBMcompatible PC using a DOS operation system and a Microsoft FORTRAN compiler (version 4.01 was used). It requires that the machine have at least $640 \mathrm{k}$ bytes of random access memory.

The program should run without any changes when later versions of the Microsoft compiler are used. The debug option should not be used since this will result in an executable file which is too large. It is recommended that the program not be run an any PC less powerful than an 80286 with an 80287 coprocessor, or excessive run times will result.

If the program is run on any other machine and/or compiler, some modifications will be required. These changes will principally apply to the input and output, the definition of files, especially the two temporary files (on a machine with more memory these files may be held in RAM if appropriate changes are made to the source code).

\subsection{Limitations}

Design of the program to run on an IBM PC under DOS led to several limitations in the size of arrays and the corresponding physical phenomena. One array, $\operatorname{TRH}(128,630)$, is used to store several variables (time series of velocity perturbations, and the transfer matrix, $\mathrm{H}$, of the matrix, $\mathrm{S}$, of spectral densities). This means that the length of the velocity time series must be less than or equal to 128 values. This, in turn, dictates the time interval if the total time elapsed is to be equal to, say, 16 rotor revolutions. For example, the $34 \mathrm{~m}$ Test Bed turning at $34 \mathrm{rpm}$ requires a total time of 28.2 seconds for 16 revolutions, which, allowing for some additional time, leads to a maximum time interval of about 0.24 seconds. This, in turn, implies an upper limit of about $2.1 \mathrm{~Hz}$ in the turbulence frequency spectrum. While most of the turbulence energy will be within this frequency, it could be undesirably restrictive and, where memory allows, the upper limit could be removed.

The other major limitation arises due to the size of the array of spatial cross spectral densities of wind speed perturbations. The dimension of this array is the total number of spatial points at which the velocity series is defined and the number of spectra is the number of elements in one triangle of this array. Limiting this number to 630 implies representing the flow over the swept area at no more than 35 points (or a 7 x 5 array). 


\subsection{Linking}

The size of the program TRES4 requires that it be divided into two parts in order to compile with a Microsoft compiler on a PC. This can be done by compiling the parts separately and then linking them together.

In addition, the fast Fourier transform routine, FFT842, must be separately compiled and linked with the final executable file. This routine is one of many that will perform the necessary operation, but it is the routine that is called in TRES4.

\section{AIRFOIL DATA}

All the necessary airfoil data are read in by subroutine READAIR, and a sample of an input file is included as Appendix E. This input file must adhere to the following format restrictions.

1. The file may contain lift and drag coefficients for any number of airfoil shapes, but no more than five can be read by one job.

2. Each airfoil may have coefficients listed at up to five Reynolds numbers.

3. Up to 50 angles of attack may be listed for each set of data.

4. If data at more than one Reynolds number are given for a certain airfoil, then the sets must be placed in order of ascending Reynolds number.

5. The last angle of attack in each set must be 180.0 (exactly).

6. The angles of attack used for different airfoils or for different Reynolds numbers of the same airfoil do not have to be the same (in value or in total number).

7. The file must end with "ENDFILE."

8. Each set or group of data must begin with a line having the eight-character alphanumeric airfoil identifier in the first field (corresponding to the alphanumeric used in the basic input data and described in Section 4.3)

9. The second line of each set contains the following, in (F10.0,2Fl0.4) format:

$\operatorname{RE}(i, j)$

$\operatorname{AS}(i, j)$

$\operatorname{CDMIN}(\mathrm{i}, \mathrm{j})$

TC(i)
Reynolds number \#j for airfoil \#i corresponding static stall angle corresponding drag coefficient at zero angle of attack to be added to all listed values thickness-to-chord ratio for airfoil \#i 
10. Subsequent lines contain in 3F10.4 format the following:
A angle of attack (degrees)
$\mathrm{CL}$ lift coefficient
$\mathrm{CD}$ drag coefficient

\section{OUTPUT VIA TRESD.FOR}

The program TRES4E can take several hours to run on an $80286 \mathrm{PC}$ when the maximum spatial array is used together with 30 or more ensembles of 16 revolutions each. To avoid having to rerun merely because the variables controlling the TRESI.OUT output are incorrect, the program TRESD.FOR can be used. This program reads the same basic input file as TRES4E.FOR together with the temporary file (TRES2.TMP) that contains the data for the psd and csd's of the output load.

A new set of data in NASTRAN format can be quickly obtained in this way. For example, if the initial settings resulted in the elimination of too many cross spectral densities, then the value of FMIN in the basic input file can be reduced, and TRESD.FOR can be run for a more acceptable set of modal load spectra.

\section{AEROELAS'TIC EFFECTS}

The displacements of the wind turbine blades (measured in the rotating frame) cause changes in the angle of attack of the relative wind. This in turn affects the aerodynamic forces experienced by the blades. This interaction between structural dynamics and aerodynamics can be described by classical theories of aeroelasticity and has been investigated by Lobitz and Ashwill (1986), Malcolm (1990), and others.

While there are only small changes on the effective stiffness and mass, the main effect is on the damping matrix. The different modes of response experience different degrees of damping. This damping can be extremely important in attenuating structural response due to stochastic loading at rotor natural frequencies.

Aeroelastic damping can be incorporated in one of two ways. It can be incorporated by estimating (largely by experience) the critical damping factors for each of the real modes and including this information in the basic input file (see Section 4.3), in conjunction with an SDAMP statement in the NASTRAN case control section.

Alternatively these effects can be included in the NASTRAN run by inserting the changes to the matrices as a series of DMIG (Direct Matrix Input - G-set) statements. These lines are generated by running a program called AEROB5.FOR, which is described below. 


\subsection{Program AEROB5.FOR}

This program is fully described and documented in Malcolm (1990). It is based on the work by Lobitz and Ashwill (1986) and predicts the same results (at normal operating speeds). The program requires two input files--one is the same NASTRAN bulk data file as was used in the TRES4 program, and the other is described below.

\subsection{Basic Input File}

A sample input file is included as Appendix $G$. The same rules as in the TRES4 input file apply concerning comment lines (they require a " $\$$ " in column 1 ).

Line 1 (free format)

RPM rpm rotational speed of rotor

ARHO $\mathrm{lb} / \mathrm{ft}^{3}$ air density

FLUT $\mathrm{Hz} \quad$ typical frequency of rotor blades. This is usually set at about 3 times the rotor speed.

$\mathrm{AB}$ fraction of the half-chord by which the center of twist is rear of the half-chord position

CMIN a minimum value for output values below which they are omitted

NSECT number of blade sections listed below

Lines $2,3 \& 4$ (A3 format)

"YES"/"NO" flag for inclusion of rotating frame effects in the calculations

"YES"/"NO" flag for inclusion of apparent mass terms in output

"YES"/"NO" flag for use of the ZSET reduced blade node option in place of the full set (see Section 4.5)

Next NSECT lines (format I4,A8,F10.2)

I

TYPE(I)

$\mathrm{CH}(\mathrm{I})$ inches section number corresponding to PBEAM id number $(100+\mathrm{I})$

8 -character alphanumeric description of airfoil profile (which must correspond to the description in the airfoil data file--see Section 6)

blade chord 


\section{REFERENCES}

P.S. Veers, "Modelling Stochastic Wind Loads on Vertical Axis Wind Turbines," Sandia National Laboratories, SAND83-1909, Sept. 1984.

I. Paraschivoiu, "Aerodynamic Analysis of the Darrieus Rotor Including Secondary Effects," J. of Energy, AIAA 7,(5), pp. 416-422, Sept. 1984.

D.W. Lobitz and T.D. Ashwill, "Aeroelastic Effects in the Structural Dynamics of Vertical Axis Wind Turbines," Sandia National Laboratories report SAND85-0957, April 1986.

P.S. Veers, "Three Dimensional Wind Simulation," Sandia National Laboratories report, SAND88-0152, March 1988.

D.J. Malcolm, "A Model for the Response of Vertical Axis Wind Turbines to Turbulent Flow. Parts 1 and 2", Sandia National Laboratories Contractor's report, SAND88-7021, July 1988.

D.J. Malcolm, "Vertical Axis Wind Turbine Turbulent Response Model," Sandia National Laboratories, Contractor's Report, SAND89-7042, Jan. 1990. 


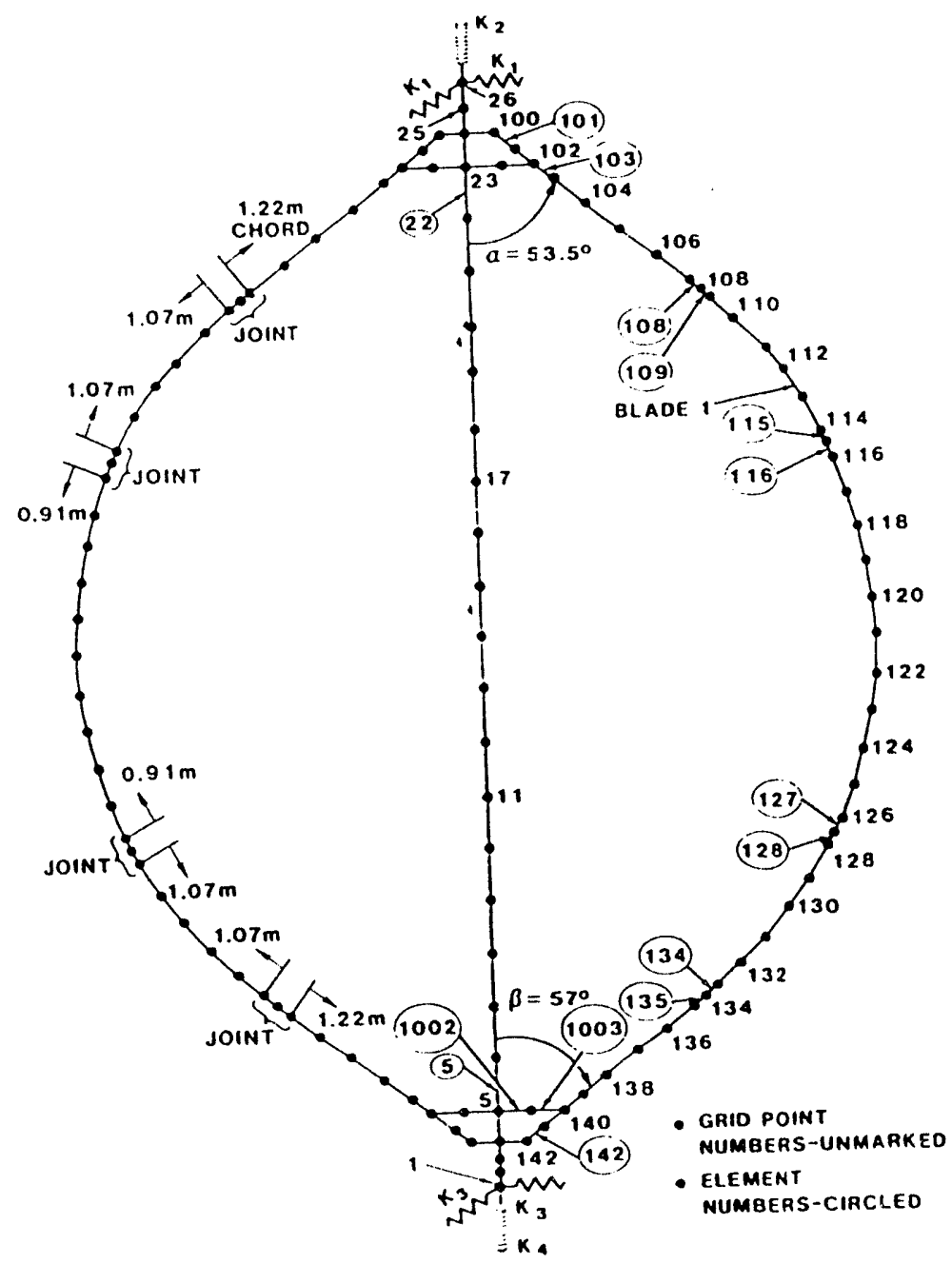

Fig. 1. Finite Element Grid 


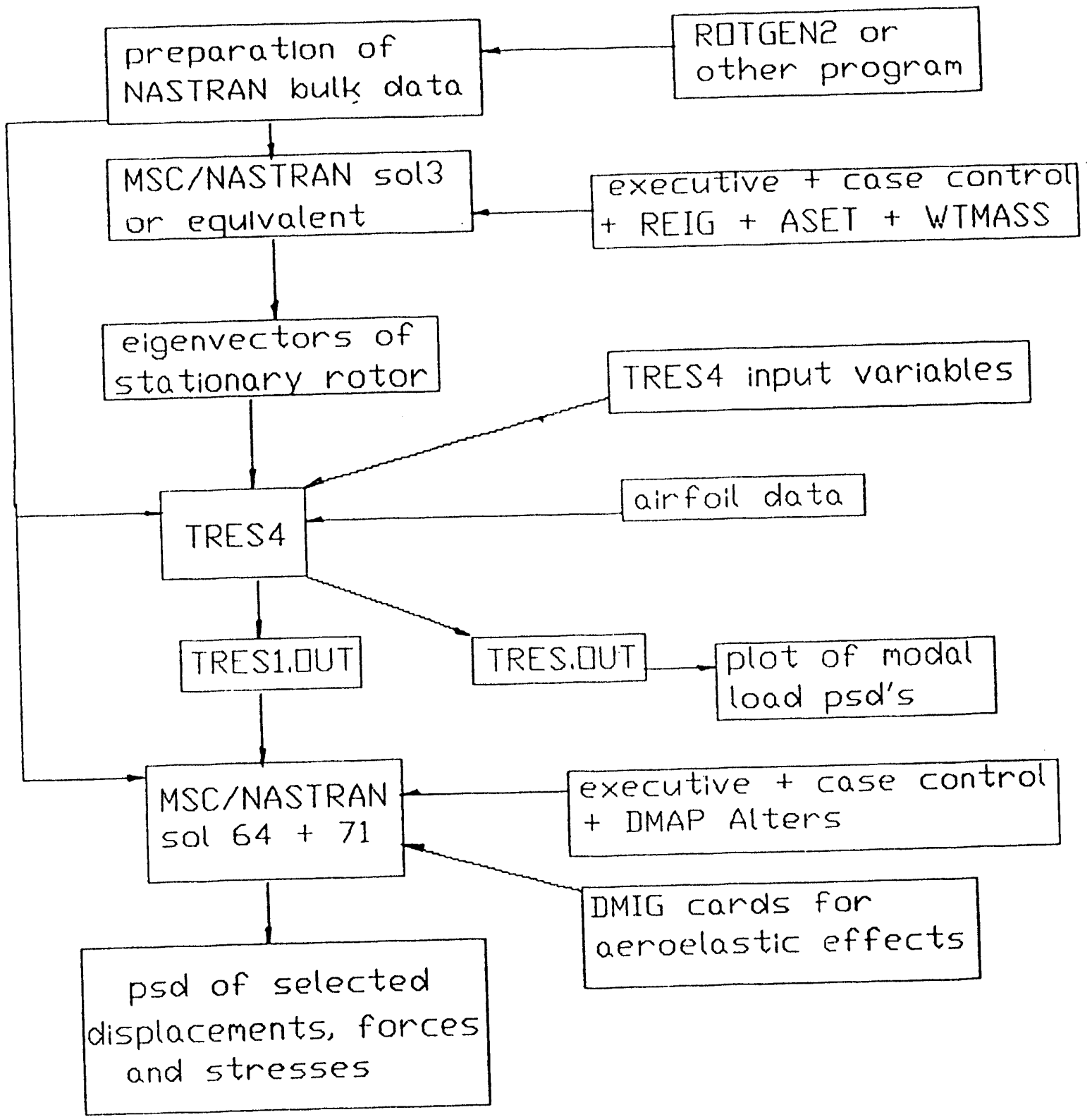

Fig. 2. Schematic of total solution 


\section{APPENDIXA}

\section{NASTRAN Bulk Data Input File}

\$TITLE=37.5/45 137.5/110 BULK DATA M6T235A W/ AER+AIR //OMG=2.0 BEGIN BULK

$\$$ D MALCOLM VERSION OF ATEST.DAT. MODIFIED TO "11-87 MODEL" MARCH' 88 $\$$ PBEAM STRESS RECOVERY MODIFIED $18 \mathrm{MARCH} 88$. LOCAL COORDS MODIFIED $\$$ COLUMN CONNECTIONS. SLBULK3-LOCAL COORDS CORRECTED 18 JULY 89.

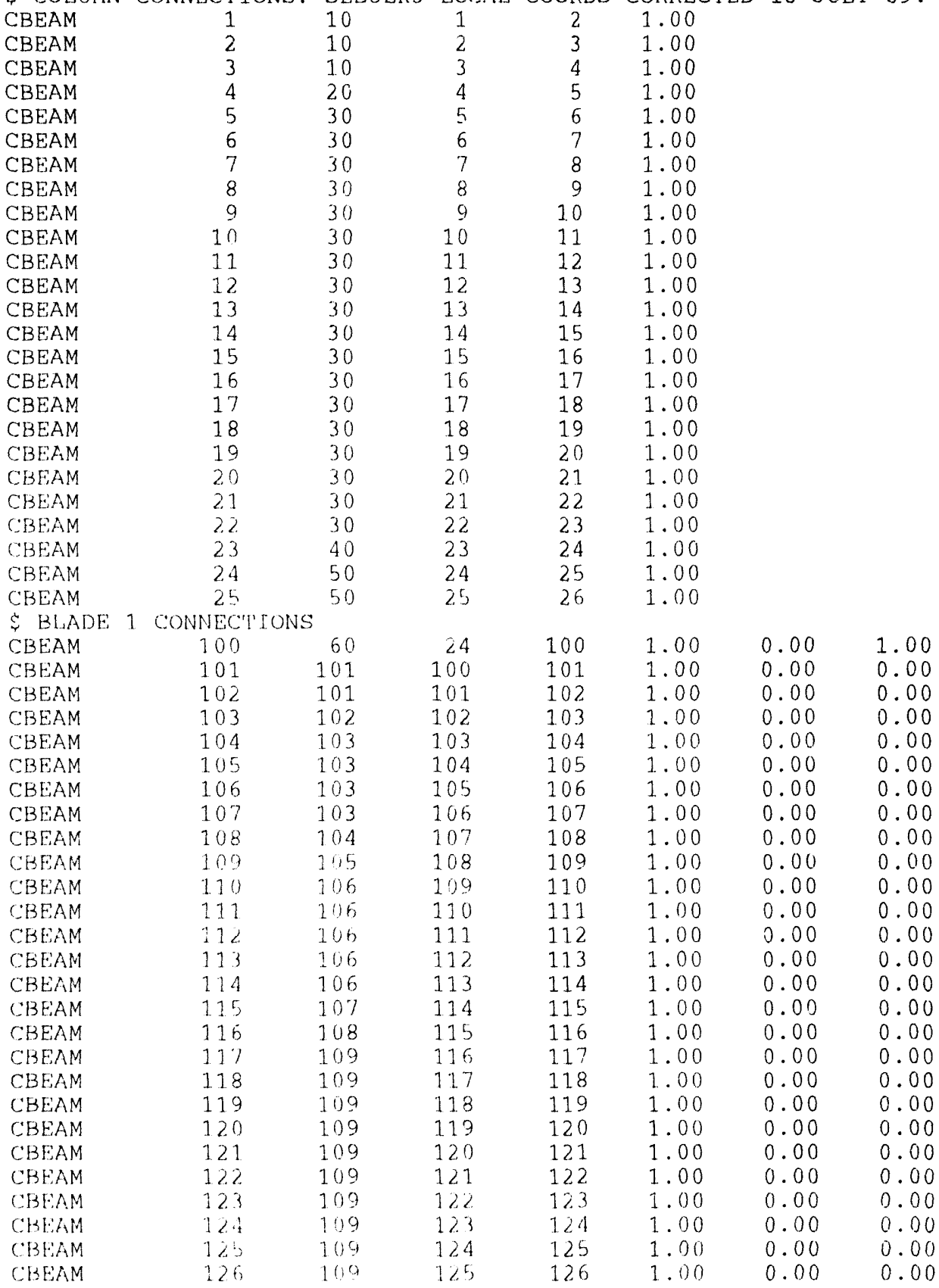




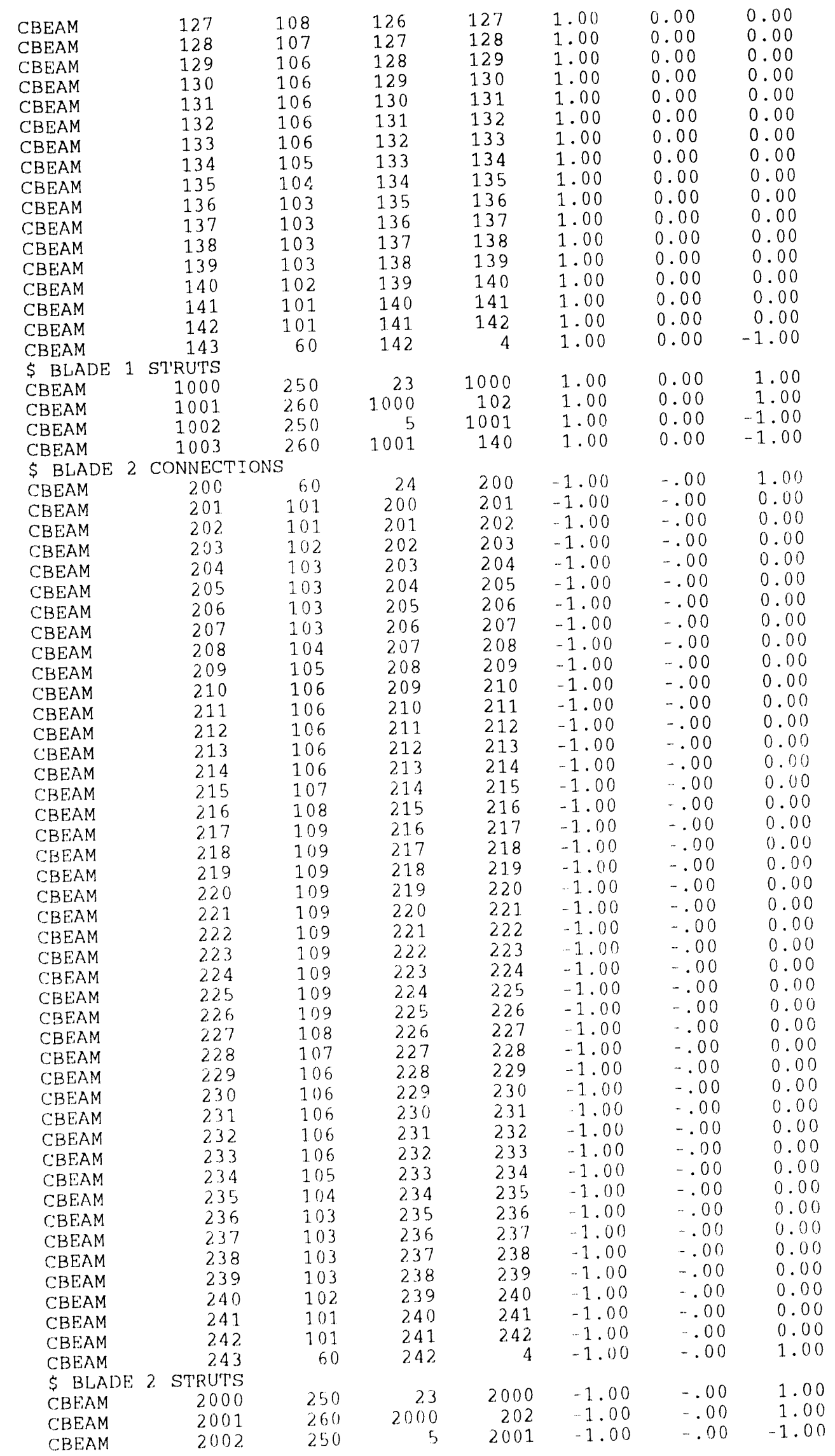




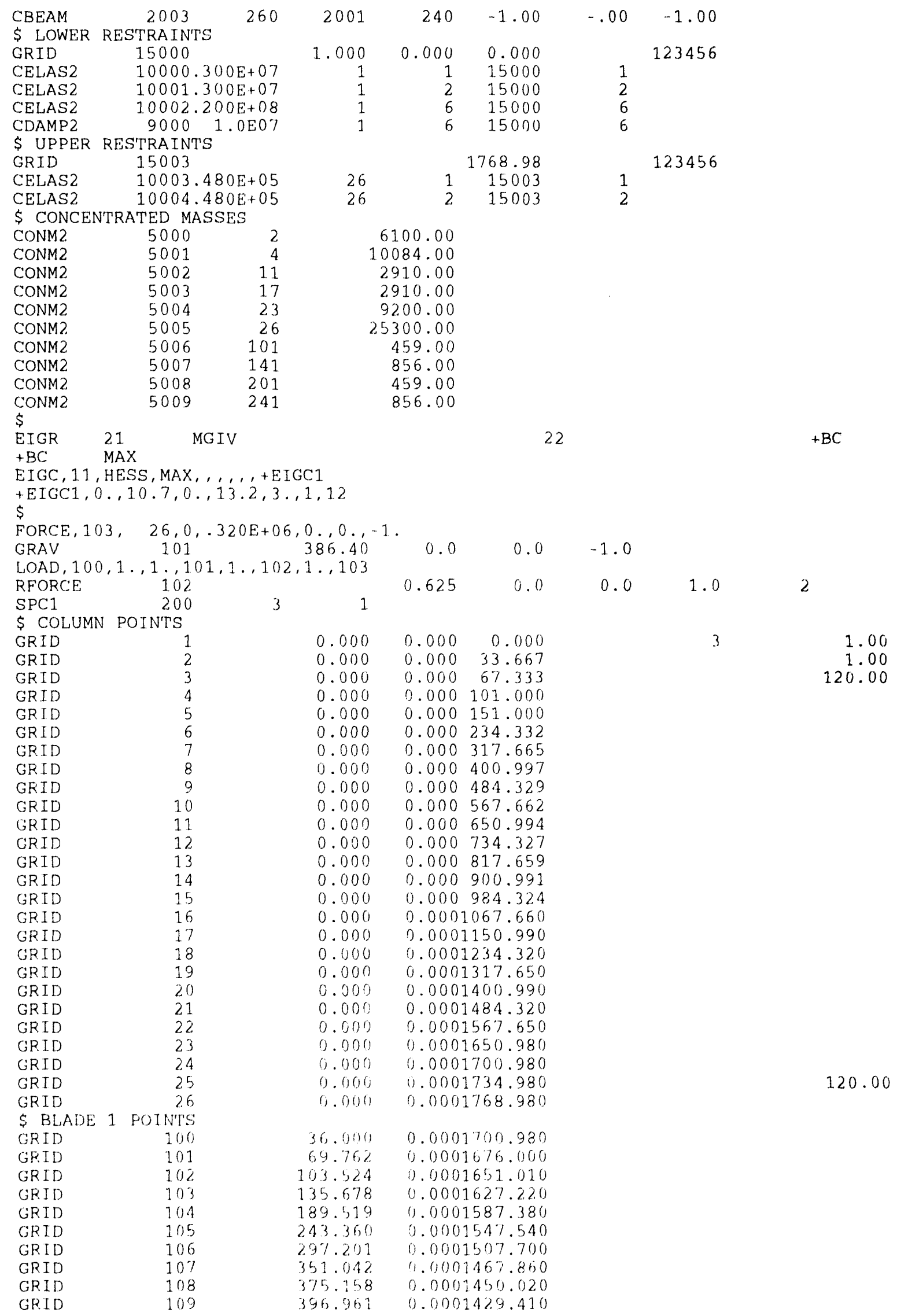




\begin{tabular}{|c|c|c|c|}
\hline GRTD & 110 & 431.132 & 0.0001395 .770 \\
\hline GRID & 111 & 463.908 & 0.0001360 .780 \\
\hline GRID & 112 & 495.236 & 0.0001324 .480 \\
\hline GRID & 113 & 525.063 & 0.0001286 .940 \\
\hline GRID & 114 & 553.340 & 0.0001248 .210 \\
\hline GRID & 115 & 570.536 & 0.0001223 .630 \\
\hline GRID & 116 & 584.366 & 0.0001197 .010 \\
\hline GRID & 117 & 611.392 & 0.0001138 .270 \\
\hline GRID & 118 & 632.674 & 0.0001077 .210 \\
\hline GRID & 119 & 648.016 & 0.0001014 .400 \\
\hline GRID & 120 & 657.278 & 0.000950 .410 \\
\hline GRID & 121 & 660.375 & 0.000885 .826 \\
\hline GRID & 122 & 656.320 & 0.000811 .952 \\
\hline GRID & 123 & 644.205 & 0.000738 .966 \\
\hline GRID & 124 & 624.175 & $0.000 \quad 667.744$ \\
\hline GRID & 125 & 596.470 & $0.000 \quad 599.142$ \\
\hline GRID & 126 & 561.424 & 0.000533 .985 \\
\hline GRID & 127 & 545.786 & $0.000 \quad 508.382$ \\
\hline GRID & 128 & 526.981 & 0.000485 .008 \\
\hline GRID & 129 & 496.172 & $0.000 \quad 448.271$ \\
\hline GRID & 130 & 463.897 & 0.000412 .815 \\
\hline GRID & 131 & 430.208 & 0.000378 .699 \\
\hline GRID & 132 & 395.161 & $0.000 \quad 345.980$ \\
\hline GRID & 133 & 358.814 & $0.000 \quad 314.712$ \\
\hline GRID & 134 & 335.678 & $0.000 \quad 295.613$ \\
\hline GRID & 135 & 310.518 & $0.000 \quad 279.274$ \\
\hline GRID & 136 & 267.887 & $0.000 \quad 251.590$ \\
\hline GRID & 137 & 225.257 & $0.000 \quad 223.905$ \\
\hline GRID & 138 & 182.626 & 0.000196 .220 \\
\hline GRID & 139 & 139.995 & 0.000168 .535 \\
\hline GRID & 1.40 & 106.448 & $0.000 \quad 146.750$ \\
\hline GRID & 141 & 71.224 & $0.000 \quad 123.875$ \\
\hline GRID & 142 & 36.000 & $0.000 \quad 101.000$ \\
\hline$\$ B L$ & STRUTS & & \\
\hline GRID & 1000 & 60.000 & 0.0001650 .980 \\
\hline GRID & 1001 & 60.000 & 0.000151 .000 \\
\hline$\$ \mathrm{BL}$ & GRID POINTS & & \\
\hline GRID & 200 & -36.000 & -.0001700 .980 \\
\hline GRID & 201 & -69.762 & -.0001676 .000 \\
\hline GRID & 202 & -103.524 & .0001651 .010 \\
\hline GRID & 203 & -1.35 .678 & -.0001627 .220 \\
\hline GRID & 204 & -189.519 & -.0001587 .380 \\
\hline GRID & 205 & -243.360 & -.0001547 .540 \\
\hline GRID & 206 & -297.201 & -.0001507 .700 \\
\hline GRID & 207 & -351.042 & -.0001467 .860 \\
\hline GRID & 208 & -375.158 & -.0001450 .020 \\
\hline GRID & 209 & -396.961 & -.0001429 .410 \\
\hline GRID & 2.10 & 431.132 & -.0001395 .770 \\
\hline GRID & 211 & -463.908 & -.0001360 .780 \\
\hline GRID & 212 & -495.236 & -.0001324 .480 \\
\hline GRID & 2.13 & -525.063 & -.0001286 .940 \\
\hline GRID & 214 & -553.340 & -.0001248 .210 \\
\hline GRID & 2.15 & -570.536 & -.0001223 .630 \\
\hline GRID & 216 & -584.366 & $\cdots .0001197 .010$ \\
\hline GRID & 217 & -611.392 & -.0001138 .270 \\
\hline GRID & 218 & -632.674 & -.0001077 .210 \\
\hline GRID & 219 & -648.016 & $\therefore .0001014 .400$ \\
\hline GRID & 220 & -657.278 & -.000950 .410 \\
\hline GRID & 221 & -660.375 & -.000885 .826 \\
\hline GRID & 222 & -656.320 & -.000811 .952 \\
\hline GRID & 2.23 & -644.205 & -.000738 .966 \\
\hline GRID & 22.4 & -624.175 & $\cdots .000 \quad 667.744$ \\
\hline GRID & 225 & .596 .470 & -.000599 .142 \\
\hline GRID & 226 & -561.424 & -.000533 .985 \\
\hline GRID & 227 & -545.786 & -.000508 .382 \\
\hline GRID & 228 & -526.981 & -.000485 .008 \\
\hline GRID & 229 & -496.172 & $\cdots .000 \quad 448.271$ \\
\hline GRID & 2.30 & 463.897 & $-.000 \quad 412.815$ \\
\hline GRID & 231 & -430.208 & $.000 \quad 378.699$ \\
\hline GRID & 232 & -395.161 & -.000345 .980 \\
\hline GRID & 233 & 358.814 & $-.000 \quad 314.712$ \\
\hline
\end{tabular}




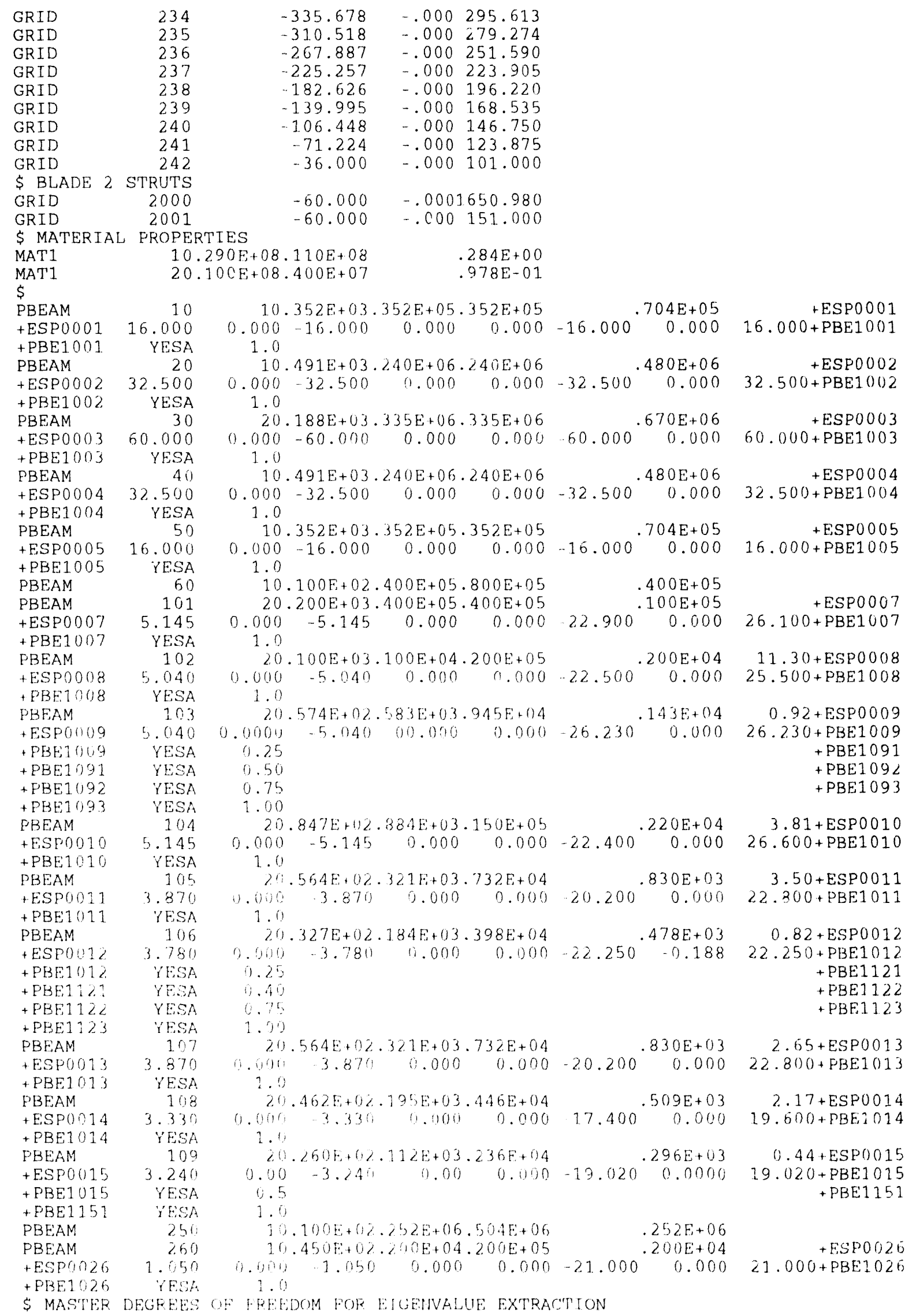


SASET $1,12,5,9,14,19,23,26$

\$ASET1, 12.3,108,115,121,127,134

SASE11, 123,208,215,221,227,234

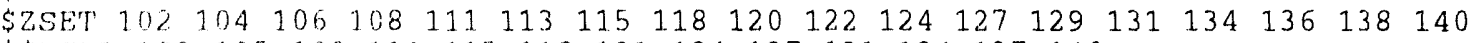

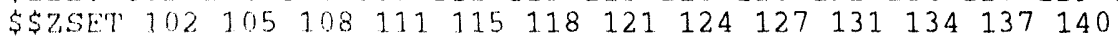

\$2SET 120121122

\$PARAM GRDPNT

\$AER $\quad 1.15 \mathrm{E} 7 \quad 2.00$

PARAM WTMASS .002588

PARAM MAXRATIO 9.E12

\$PARAM, LMODES, 22

\$PAPAM, UDRMM, - 1

\$PARAM, G, 0.0.4

\$PARAM, MODACC, +1

$\$$ ROTATING FRAME EFFECTS

PARAM OMEGA 3.5600

DMI SKEN

DMI SKEW

DMI SKEW

DMI SYM

DMI SYM

DMI SYM

DMIG; SOFTHING

DMIG SOFINING

DMIG (ORIO)

DMIS COFIOH

DMIG COHIOL

ENDDATA

1.00
1.00
1.00
1.00
3

0

0

.00
1.00

3

3
6

6

$1.1 \mathrm{E}-09$

$2.1 \mathrm{E}-09$ 


\section{APPENDIX B}

\section{Sample Solution 3 Input}






\section{APPENDIXC}

\section{Sample Solution 64 and 71 Input}

\section{Solution 64}

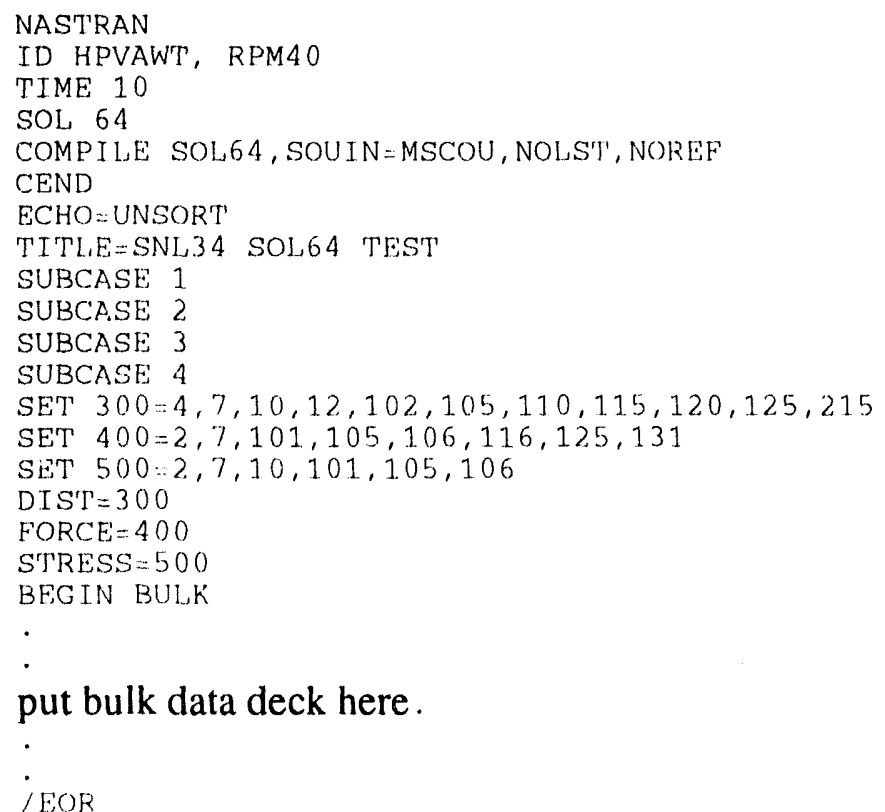

NOTE: This solution must be run in conjunction with solution 71 so that the data base is transferred from one to the other.

\section{Solution 71}

NASTRAN

A.SSIGN UNIT $=11$

ID SNLTB, TEST

T'IME: 10

SOL 71

DLAG 64

COMPILE SOL71, SOUTN=MSCSOU, NOLIST, NOREF

ALTER 1087

MATMOD

MPYAD

SYM, SIL, , , /SYMC, 15

\$PLACE BASIC SYM $6{ }^{*} 6$ IN $\mathrm{G}^{*} \mathrm{G}$ MATRIX

PARAMR PARAMR MGG, SYMG , /KGSYM//-1 \$MPLY MGG BY - SYMG

$A D D$ \$MOD'TRL EQUIV MATMOD MPYAD PARAMR PARAMR $A D D$ EQUIV $1 /$ 'MPY'/S, N, OMEGASQ/V, Y, OMEGA / V, Y, OMEGA \$OMEGASQ=OMEGA2 $/ /$ COMPLEX'//S, N, OMEGASQ/0.0/V, N, COMEGASO \$COMEGASQ=OMEGASQ 0.0 KGSYM, K2PP/KSOFT/COMEGASQ \$KSOPT=KGSYM*W\} +K2GG KSOFT////6/ \$ KSOF'T', K2.PP/ALWAYS SKEW, SIL, , , / SKEWG , 15 MGG, SKEWG, MGSKEW $\$$ PLACE BASIC SKEW $6{ }^{*} 6$ IN ${ }^{*}{ }^{*}$ MATRIX SMPLY MGG BY SKEWG

//'MPY'/S, N, OMEGA2/V,Y,OMEGA/2.0 \$OMEGA2 $=2$ *OMEGA $/ /{ }^{\prime}$ COMPLEX'//V, $N$, OMEGA2/0 $0 / \mathrm{S}, \mathrm{N}, \mathrm{COMEGA2} \$ \mathrm{COMEGA2}=(\mathrm{OMEGA} 2,0.0)$ MGSKEW, $32 \mathrm{PP} / \mathrm{CORIOLIS/COMEGA2}$ \$CORIOLIS=COMEGA2 *MGSKEW+K2 PP CORIOLIS,BZPP/ALWAYS \$

ALTER FOR PH REVISION

ALTER 1134 


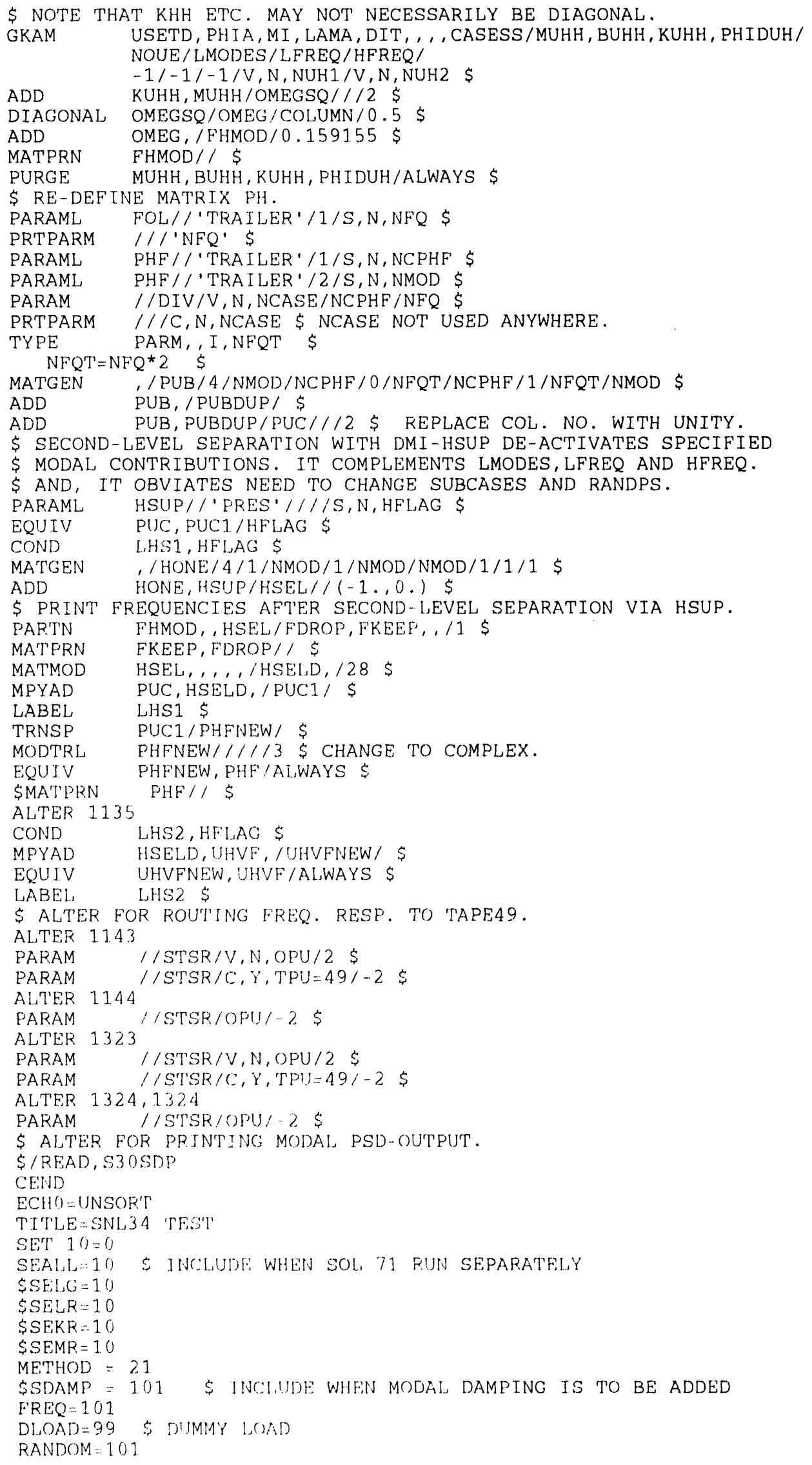




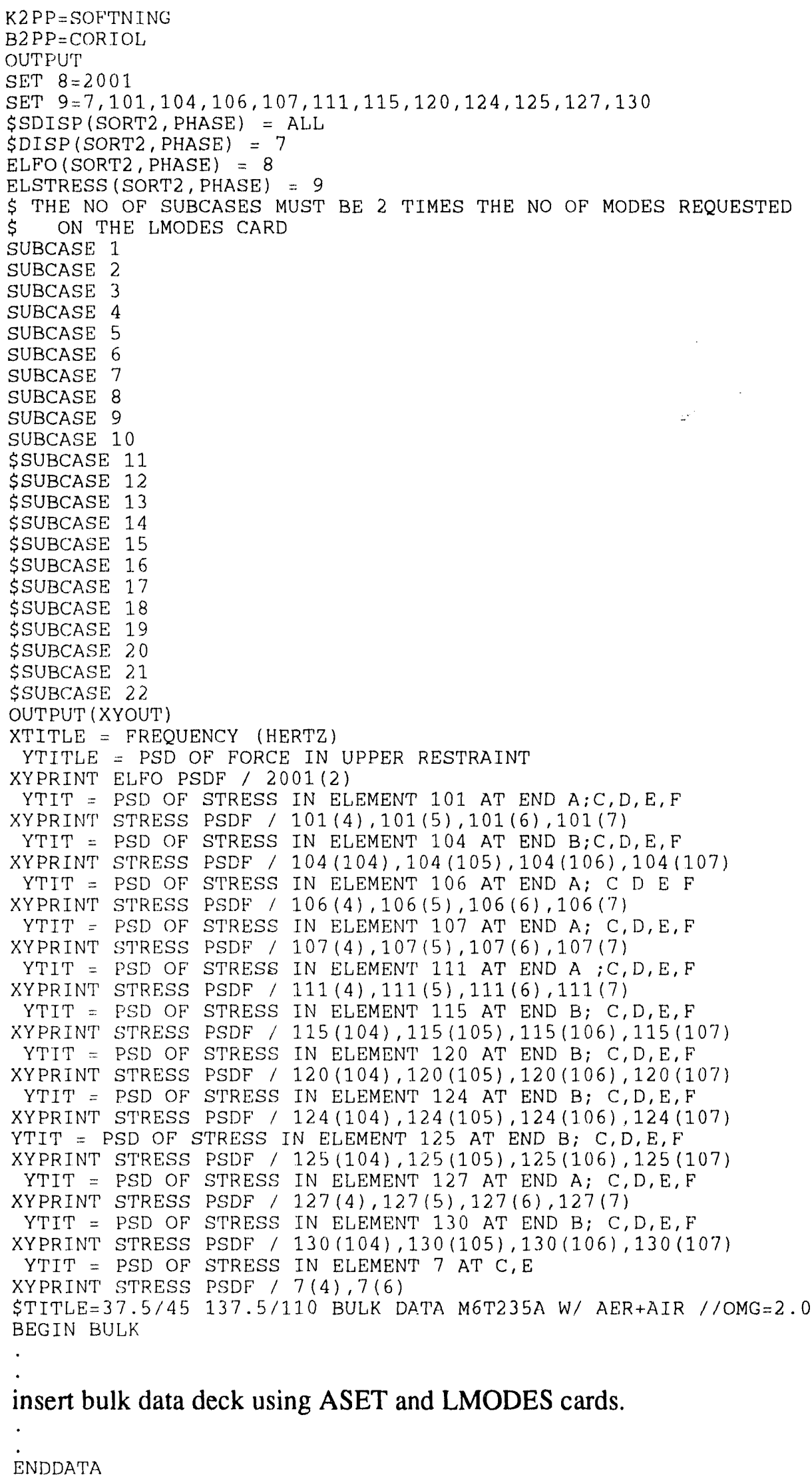




\section{APPENDIX D}

\section{Sample TRES1.OUT File}






\begin{tabular}{|c|c|c|c|c|c|c|c|c|}
\hline RANDPS & 101 & 1 & 2 & & -1.0 & 1007 & & \\
\hline TABRND1. & 1007 & & & & & & & + TAB1 023 \\
\hline+ TAB1.023 & .000 & $.0000+10$ & .156 & $.0000+0$ & .313 & $.3811+5$ & .469 & $.8285+6+\mathrm{TAB} 1024$ \\
\hline+ TAB1024 & .625 & $.1007+6$ & .781 & $.6319+5$ & .938 & $.2 .992+5$ & 1.250 & $.0000+0+\mathrm{TAB} 1.025$ \\
\hline+ TAB1025 & 1.406 & $.7294+5$ & & $.8934+4$ & & $.9023+4$ & & $.0000+0+\mathrm{TAB} 1026$ \\
\hline+ TAB1026 & ENDT & & & & & & & \\
\hline RANDPS & 101 & 1 & 3 & 1.0 & & 1008 & & \\
\hline TABRND1 & 1008 & & & & & & & +TAB1027 \\
\hline+ TAB1027 & .000 & $.0000+0$ & .156 & $.0000+0$ & .313 & $.7255+4$ & .469 & $.0000+0+$ TAB1 028 \\
\hline+ TAB1028 & .625 & $.0000+0$ & .781 & $.6795+5$ & .938 & & 1.094 & $.1440+5+$ TAB 1029 \\
\hline +TAB1 029 & 1.406 & $.0000+0$ & 1.563 & $.593 i+4$ & 1.719 & $.9995+4$ & 1.875 & $.8289+4+\mathrm{TAB} 1030$ \\
\hline +TAB10.30 & ENDT & & & & & & & \\
\hline RANDPS & 101 & 1 & 3 & -1.0 & & 1009 & & \\
\hline TABRND1 & 1009 & & & & & & & + TAB1031 \\
\hline+ TAB1031 & .000 & $.4059+6$ & .156 & $.2004+5$ & .313 & $.7022+4$ & .469 & $.7466+5+\mathrm{TAB} 1032$ \\
\hline$+\mathrm{TAB} 1032$ & .625 & $.0000+0$ & .781 & $.0000+$ & .938 & $.4448+5$ & 1.094 & $.0000+0+$ TAB 1033 \\
\hline+ TAB1033 & 1.719 & $.0000+0$ & 1.875 & $.6437+4$ & ENDT & & & \\
\hline RANDPS & 101 & 1 & 3 & & 1.0 & 1010 & & \\
\hline TABRND1 & 1010 & & & & & & & $+\Gamma A B 1034$ \\
\hline +TAB1034 & .000 & $.0000+0$ & .156 & $.3661+5$ & .313 & $.5989+$ & .469 & $.5539+5+\mathrm{T}$ \\
\hline+ TAB1035 & .625 & $.3581+4$ & .781 & $.6795+5$ & .938 & $.1169+5$ & 1.094 & $.4880+4+$ TAB1036 \\
\hline $\begin{array}{l}1036 \\
\text { PS }\end{array}$ & ENDT & 3 & 3 & & & 101 & & \\
\hline $\begin{array}{l}\text { RANDPS } \\
\text { TABRND1 }\end{array}$ & $\begin{array}{r}101 \\
1011\end{array}$ & 2 & 3 & 1.0 & & 1011 & & $+\mathrm{TAB}=037$ \\
\hline $\begin{array}{l}\text { +TAB10 } 37 \\
+ \text { TAB1 }\end{array}$ & .000 & $.1954+5$ & .156 & $.3453+5$ & .313 & $.1138+5$ & .469 & $.5485+4+T$ \\
\hline 038 & .625 & $.1835+6$ & .781 & .42 .11 & .938 & $.7770+$ & 1.875 & $.0000+0+$ TAB 1039 \\
\hline+ TAB1039 & ENDT & & & & & & & \\
\hline RANDPS & 101 & 2 & 3 & -1.0 & & 1012 & & \\
\hline HD1 & 1012 & & & & & & & + TAB1040 \\
\hline +TAB1040 & .000 & $.0000+0$ & .156 & $.5043+5$ & .313 & $.1238+6$ & .459 & $.0000+0+\mathrm{T} /$ \\
\hline +'TAB1041 & .625 & $.0000+0$ & 781 & .7390 & 938 & .5522 & 1.094 & $.2948+5+\mathrm{TAB} 1042$ \\
\hline+ TAB1042. & 1.250 & $.0000+0$ & 1.406 & $.0000+0$ & 1.563 & $.1539+5$ & 1.719 & $.25 \cdot 3+4+$ TAB 153 \\
\hline 1043 & 2.875 & $.4948+4$ & ENDT & & & & & \\
\hline RANDPS & 101 & 2 & 3 & & 1.0 & 1013 & & \\
\hline TABRND1 & 1013 & & & & & & & $+T A B 1044$ \\
\hline+ TABI044 & .000 & $.9351+4$ & .156 & $.0000+0$ & .313 & $.0000+0$ & .469 & $.8523+6+$ TAB1045 \\
\hline+ TAB1045 & .625 & $.1004+5$ & .781 & $.8388+4$ & .938 & $.7829+5$ & 1.09 .4 & $.7441+5+$ TAB 1046 \\
\hline+ TAB1046 & 1.250 & $.0000+0$ & 1.406 & $.2391+5$ & 1.563 & $.1928+4$ & 1.719 & $.0000+0+T A B]: 47$ \\
\hline+ TAB1047 & 1.875 & $.3000+4$ & FHDT & & & & & \\
\hline RANDPS & 101 & 2 & 3 & & $-1 . f$ & 1014 & & \\
\hline TABRIID1 & 1014 & & & & & & & $+T A B 1048$ \\
\hline+ TAB1048 & .000 & $.0000+0$ & .156 & $.0000+0$ & .313 & $.9841+5$ & $.46,9$ & $.0000+0+\mathrm{TAB} 1049$ \\
\hline+ TAB 1049 & .625 & .104 & .781 & .0000 & .938 & .2338 & 1.094 & $.7657+5+T A B 1050$ \\
\hline+ TAB1050 & 1.250 & $.0000+0$ & 1.406 & $.5209+5$ & .563 & $582+4$ & 1.875 & $.2333+4+\mathrm{TAB} 1051$ \\
\hline
\end{tabular}




\section{APPENDIXE}

\section{Sample Airfoil Data File}

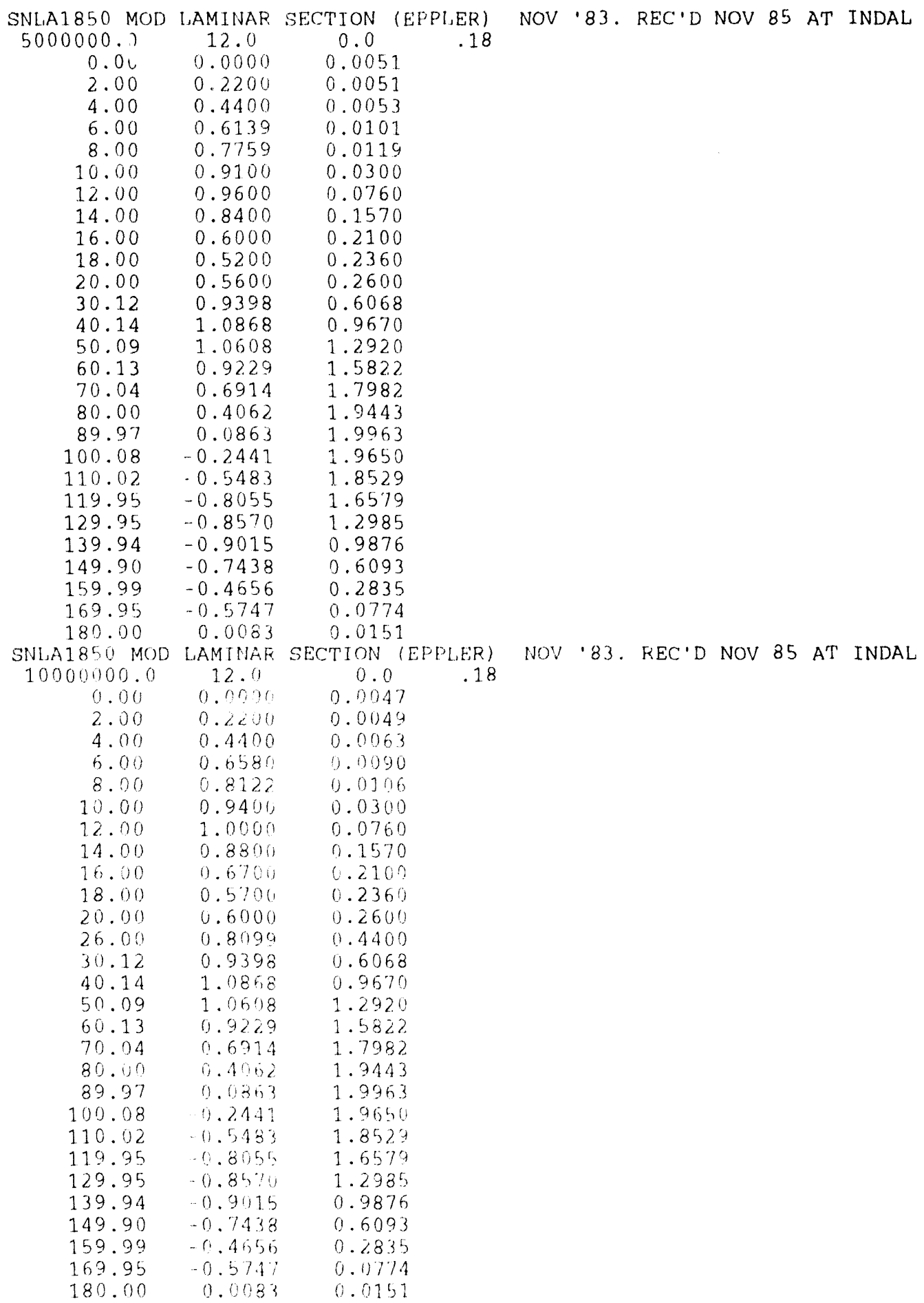




\section{APPENDIXF}

\section{Sample Basic Input File (for 34m Test Bed)}

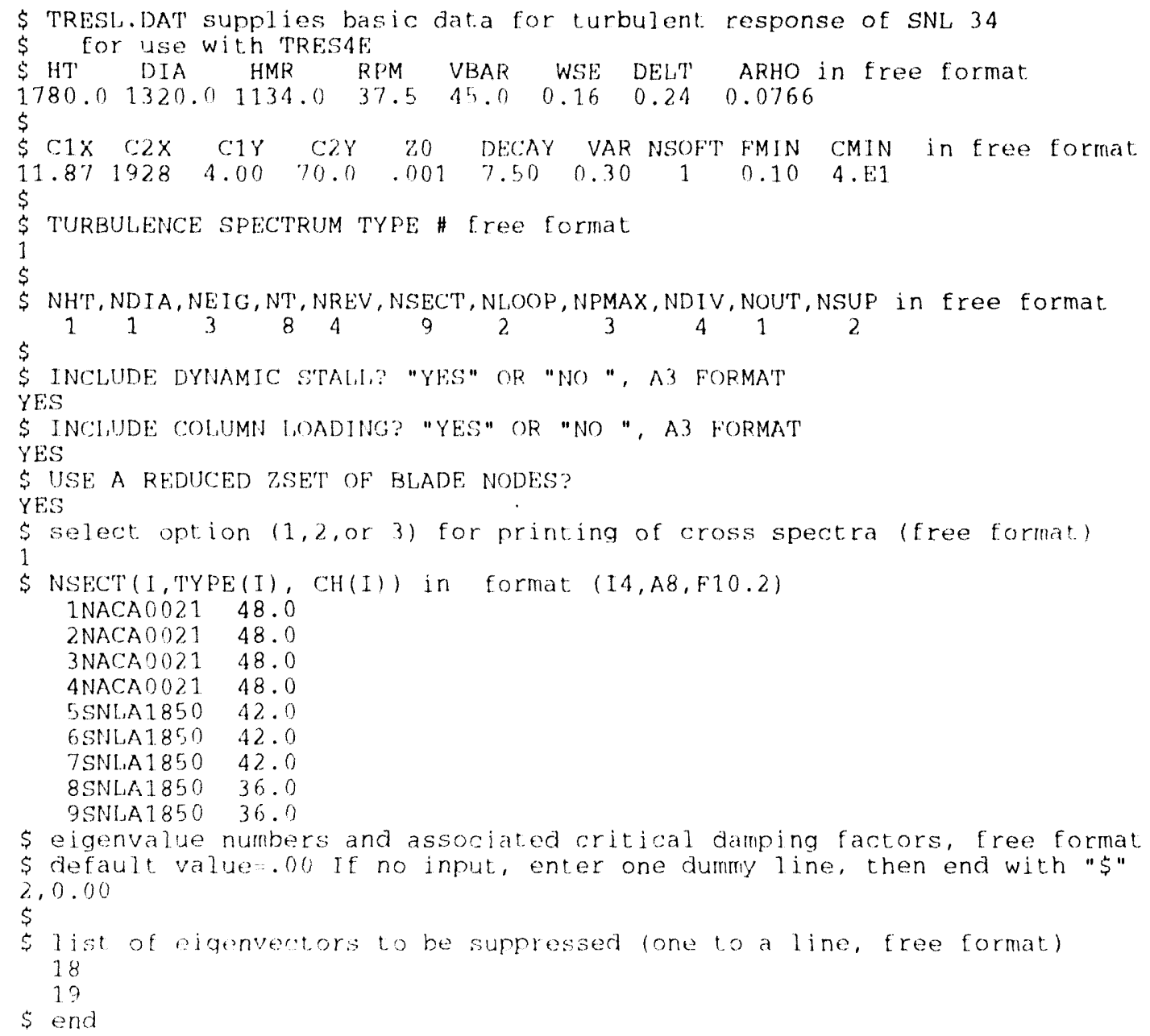




\section{APPENDIXG}

\section{Sample Basic Input File for AEROB5.FOR}

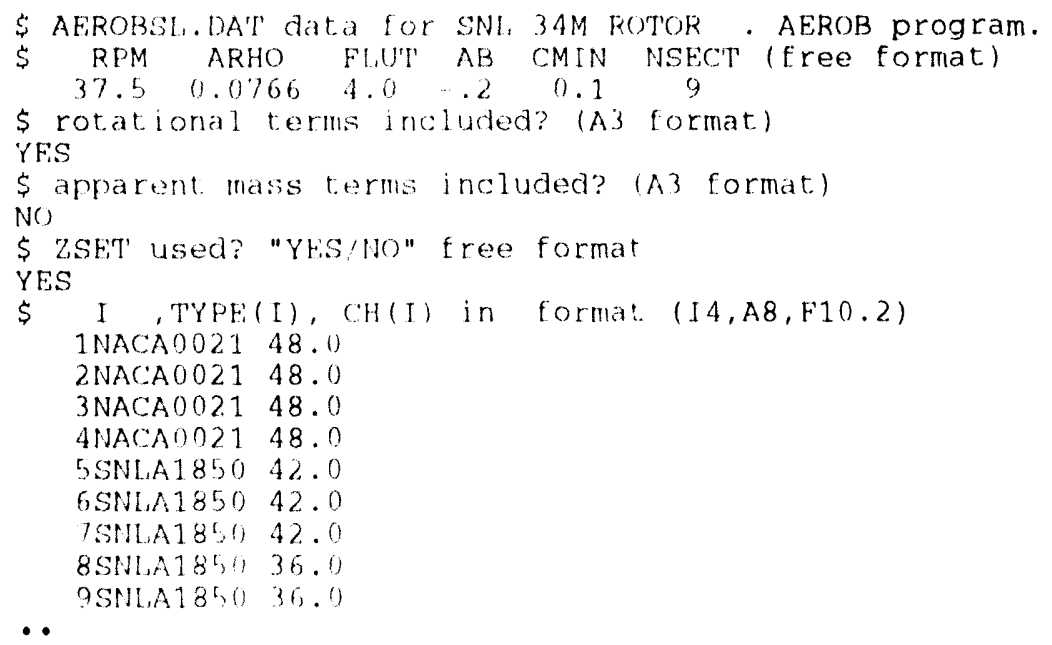


DISTRIBUTION:

R. E. Akins

Washington \& Lec University

P.O. Box 735

Lexington, VA 24450

M. Anderson

Renewable Energy Systems, Lid.

Eaton Court, Maylands Avenue

Hemel Hempstead

Herts HP2 7DR

ENGLAND

M. P. Ansell

School of Matcrial Science

University of Bath

Claverton Down

Bath BA2 7AY

Avon

ENGLAND

H. Ashley

Dept. of Acronautics and

Astronautics Mechanical Engr.

Stanford University

Stanford, CA 94305

Earl Ausman

Polarconsort Alaska

1503 W. 33rd Avenue

Suilc 310

Anchorage, AK 99530

K. Bergey

University of Oklahoma

Acro Engineering Department

Norman, OK 73069

J. Beurskens

Programme Manager for

Renewable Energies

Netherlands Encrgy Research

Foundation ECN

Westerduinweg 3

P.O. Box 1

1755 ZG Petten (NH)

THE NETHERLANDS

J. R. Birk

Electric Power Rescarch Institute 3412 Hillview Avenue

Palo Alto. CA 94.304
N. Butler

Bonneville Power Administration P.O. Box 3621

Portland, OR 97208

C. P. Butterficld

NREL

1617 Cole Boulevard

Golden CO 80401

R. N. Clark

USDA

Agricultural Research Service

Bushland, TX 79012

C. Coleman

Northern Power Systems

Box 6.59

Morelown, VT 05660

O. de Vries

National Acrospace Laboratory

Anthony Fokkerweg 2

Amsterdam 1017

THE NETHERLANDS

E. A. DeMco

Electric Power Research Instilute 3412 Hillview Avenue

Palo Allo, CA 94304

J. B. Dragı

Institute for Wind Energy

Faculty of Civil Engineering

Delfi University of Technology

Stevinweg 1

2628 CN Delft

THE NETHERLANDS

O. Dyes

Wind/Hydro/Ocean Div.

U.S. Department of Energy

1000 Independence Avenue, SW

Washington. DC 20585
A. J. Eggers, Jr.
RANN, Inc.
260 Sheridan Ave., Suite 414
Palo Alto, CA 94306 
D. M. Eggleston

DME Enginecring

P.O. Box 5907

Midland, TX 79704-5907

A. F. Abdel Azim El-Sayed

Dept. of Mechanical Design \&

Power Engincering

Zagazig University

3 El-lais Strect

Zeitun

Cairo 11321

EGYPT

J. Ereaux

PR No. 5

Bolton, Ontario L7E 5S 1

CANADA

R. A. Galbraith

Dept. of Acrospace Engineering

James Watt Building

University of Glasgow

Glasgow G12 8QG

SCOTLAND

A. D. Garrad

Garrad Hasson

9-11 Saint Stephen Street

Bristol BSI IEE

ENGLAND

P. R. Goldman

Wind/Hydro/Ocean Division

U.S. Department of Energy

1000 Independence Avenue

Washington. DC 20585

I. J. Graham

Dept. of Mechanical Engineering

Southern University

P.O. Box 9445

Baton Rouge, LA 70813-9445

G. Gregorck

Aeronautical \& Astronautical

Dept.

Ohio State University

2300 West Case Road

Columbus, $\mathrm{OH} 43220$
N. D. Ham

Aero/Astro Dept.

Massachusetts Institute of

Technology

77 Massachuselts Avenue

Cambridge, MA 02139

L. Helling

Librarian

National Atomic Museum

Albuquerque, NM 87185

T. Hillesland

Pacific Gas and Electric Co.

3400 Crow Canyon Road

San Ramon, CA 94583

E. N. Hinrichsen

Power Technologies, Inc.

P.O. Box 1058

Schenectady, NY 12301-1058

S. Hock

Wind Energy Program

NREL

1617 Cole Boulevard

Boulder, CO 80401

W. E. Hollcy

U.S. WindPower

6952 Preston Avenue

Livermore, CA 94550

M. A. Ilyan

Pacific Gas and Electric Co.

3400 Crow Canyon Road

San Ramon, CA 94583

K. Jackson

Dynamic Design

123 C Street

Davis. CA 95616

O. Krauss

Division of Engineering Research

Michigan State University

East Lansing. MI 48825

V. Laccy

Indal Technologies, Inc.

3570 Hawkestone Road

Mississauga, Ontario L5C 2V8

CANADA 
A. Lancville

Facully of Applied Science

University of Sherbrooke

Sherbrooke. Quebec JIK 2R I

\section{CANADA}

G. G. Leigh

New Mexico Engineering

Rescarch Institute

Campus P.O. Box 25

Albuquerque, NM 87131

\section{K. Liljegren}

1916 Pepper Drive

Altadena CA 9100-3523

R. R. Loose, Director Wind/Hydro/Occan Division U.S. Department of Energy 1000 Independence Ave., SW Washington, DC 20585

R. Lynelle

R. Lyncttc \& Assoc., Inc. 15042 NE 40th Street

Suite 206

Redmond. WA 98052

P. H. Madsen

Riso National Laboratory

Posthox 49

DK-4000 Roskilde

DENMARK

D. Malcolm (10)

R. Lynctte \& Associates, Inc.

15042 N.E. 40 th Strect, Suitc 206

Redmond. WA 980.52

J. F. Mandcll

Montana State University

302 Cablcigh Hall

Bozcman. MT 59717

B. Massc

Institut de Recherche d'Hydro-Quebec

18(0) Montec Ste-Julic

Varennes, Quebec J3X IS I

CANADA

G. MeNerney

U.S. Windpower, Inc.

6952 Preston Avenuc

Livermore, CA 94550
R. N. Meroney

Dept. of Civil Enginecring

Colorado State University

Fort Collins, CO 80521

D. Morrison

New Mexico Enginecring

Research Institutc

Campus P.O. Box 25

Albuquerque, NM 87131

V. Nelson

Department of Physics

West Texas State University

P.O. Box 248

Canyon, TX 79016

G. Nix

NREL

1617 Cole Boulevard

Golden, CO 80401

J. W. Oler

Mechanical Engineering Dept.

Texas Tech University

P.O. Box 4289

Lubbock, TX 79409

D. I. Page

Energy Technology Support Unit

B 156.7 Harwcll Laboratory

Oxfordshire, OXII ORA

ENGLAND

C. Paquelle

The American Wind Energy Association

777 N. Capitol Strect, NE

Suite 805

Washinglon, DC 2000)2

I. Paraschivoiu

Dept. of Mechanical Engincering

Fcolc Polytecnique

CP $6(0) 79$

Succursale A

Montreal, Quchec H3C 3A7

CANADA

T. F. Pedersen

Riso National Laboratory

Postbox 49

DK-4(O) Roskilde

DENMARK 
H. Petersen

Riso National Laboratory

Postbox 49

DK-4000) Roskilde

DENMARK

R. G. Rajagopalan

Acrospace Enginecring Department

lowa State Universily

404 Town Engineering Bldg.

Ames, IA 50011

R. Rangi

Manager, Wind Technology

Depl. of Energy, Mines and Resources

580 Bocth 7th Floor

Ottawa, Ontario KIA OEA

CANADA

M. G. Real, President

Alpha Rcal Ag

Feldeggstrasse 89

CH 8008 Zurich

SWITZERLAND

R. L. Scheffler

Research and Development Dept.

R(x)m 497

Southern California Edison

P.O. Box 8(X)

Rosemead, CA 91770)

L. Schienhein

Battelle-Pacific Northwest Laboratory

P.O. Box 999

Richland, WA 993.52

T. Schweizer

Princeton Economic Research, Inc.

1230) Twinbrook Park way

Suitc 6.5)

R(xkville, MD 208.52

D. Sharpe

Dept. of Acronautical Enginecring

Queen Mary College

Mile End Road

London, EI 4NS

ENGILAND

J. Sladky, Jr.

Kinctics Ciroup, Inc.

P.O. Box 1071

Mercer Island, WA 98(140)
M. Snyder

Acro Enginecring Department

Wichita State University

Wichita, KS 67208

L. H. Soderholm

Agricultural Enginecring

R(x)m 213

lowa State University

Ames, IA 50010

W. J. Stcelcy

Pacific Gas and Electric Co.

3400) Crow Canyon Road

San Ramon, CA 94583

F. S. Sloddard

Second Wind, Inc.

7 Davis Square

Somerville, MA 02144

D. Taylor

Alternative Energy Group

Walton Hall

Open University

Milton Keynes MK7 6AA

UNITED KINGDOM

G. P. Tennyson

DOE/AL/ETD

Albuquerque. NM 87115

W. V. Thompson

410 Ericwood Court

Manteca, CA 95336

R. W. Thresher

NREL

1617 Cole Boulevard

Golden, CO 80401

K. J. Touryan

3701 Hawkins Strect, NE

Albuquerque, NM 87109-4512

W. A. Vachon

W. A. Vachon \& Associates

P.O. Box 149

Manchester. MA 01944

P. Villecoy

Faculty of Applied Science

University of Sherbrooke

Sherbrooke, Quebec JIK 2R I

CANADA 
T. Watson

Canadian Standards Association

178 Rexdale Boulcvard

Rexdalc, Ontario M9W 1R3

CANADA

L. Wendell

Battelle.Pacific Northwest

Laboratory

P.O. Box 999

Richland, WA 99352

W. Wentz.

Acro Engineering Department

Wichita State University

Wichita, KS 67208

R. E. Wilson

!Acchanical Enginecring Dept.

Oregon State University

Corvallis, OR 97331

M. Zuteck

MDZ Consulting

931 Grove Street

Kemah, TX 77565
M.S. 0100 Document Processing (10)

For DOE/OSTI

M.S. 0167 J. C. Clausen

M.S. 0437 E. D. Reedy

M.S. 0439 C. Dohrmann

M.S. 0439 D. W. Lobitz

M.S. 0439 D. R. Martinez

M.S. 0443 J. G. Arguello

M.S. 0443 H. S. Morgan

M.S. 0447 G. H. James HI

M.S. 0447 J. P. Lauffer

M.S. 0557 T. J. Baca

M.S. 0557 T. G. Carne

M.S. 0557 P.S. Veers

M.S. 0619 Technical Publications

M.S. 0708 H. M. Dodd (20)

M.S. 0708 T. D. Ashwill

M.S. 0708 D. E. Berg

M.S. 0708 D. P. Burwinkle

M.S. 0708 M. A. Rumsey

M.S. 0708 L. L. Schluter

M.S. 0708 H. J. Sutherland

M.S. 0827 G. F. Homicz

M.S. 0833 J. H. Strickland

M.S. 0899 Technical Library (5)

M.S. 9018 Central Technical Files 

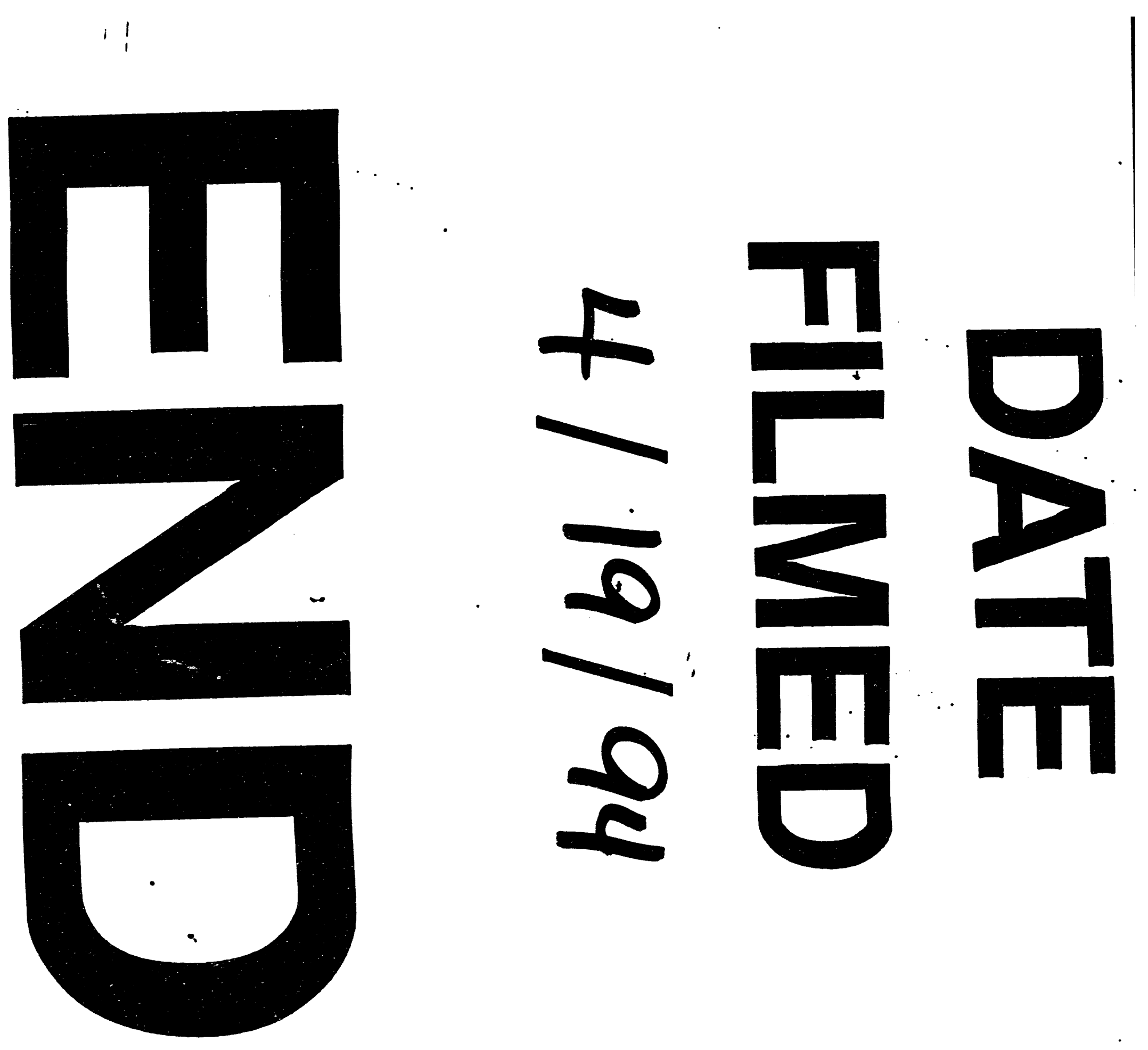
